\title{
EARTHQUAKES AND GEOMAGNETIC DISTURBANCES
}

\author{
A.V. Guglielmi \\ Schmidt Institute of Physics of the Earth RAS, \\ Moscow, Russia, guglielmi@mail.ru
}

\section{B.I. Klain}

Borok Geophysical Observatory the Branch of Schmidt Institute of Physics of the Earth RAS,

Borok, Russia, klb314@mail.ru

\author{
N.A. Kurazhkovskaya \\ Borok Geophysical Observatory the Branch of Schmidt \\ Institute of Physics of the Earth RAS, \\ Borok,Russia,knady@borok.yar.ru
}

\begin{abstract}
The article addresses the problem of the connection of earthquakes with geomagnetic phenomena. We have carried out an experimental study using a method based, firstly, on the separation of periods of geomagnetic activity into extremely quiet and disturbed, and, secondly, on the description of seismic activity with an index called the global daily magnitude (GDM). By analyzing the NEIC earthquake catalog of the US Geological Survey over a 20-year period from 1980 to 1999, we have shown that the planetary activity of earthquakes under extremely quiet geomagnetic conditions is noticeably higher than under disturbed conditions. The detected tendency for seismic activity to increase in extremely quiet periods of geomagnetic activity has indirectly been confirmed by the analysis of 35
\end{abstract}

earthquakes with magnitude 8 and higher, which occurred on Earth from 1980 to 2019. We have found that in extremely quiet geomagnetic conditions, the probability of the occurrence of strong earthquakes is noticeably higher. The result qualitatively confirms the assumption of a change in the regime of seismic activity due to the influence of alternating magnetic fields on the ductility of rocks.

Keywords: seismology, geomagnetism, Gutenberg-Richter law, magnetic storms, magnetoplasticity, earthquake ensemble, statistical sum, entropy.

\section{INTRODUCTION}

Physics of earthquakes is a fairly new field of science (about development of modern seismology, see [Davison, 1927; Guglielmi, 2017; Guglielmi, Zavyalov, 2018]). Being originally a purely empirical science, over time it has been enriched with definitions, theoretical models, and conceptual views. Shortly after, a question arose about possible existence of external factors that affect the probability of rock discontinuity resulting in an earthquake. In the context of this paper, it is reasonable to mention the pioneer work [Orlov, 1887]. The author put forward an idea about a connection between earthquakes and geomagnetic phenomena (see also [Mascart, 1887; Bauer, 1906]). The question as to how geomagnetic disturbances influence earthquake activity is still debated (see, e.g., [Buchachenko, 2019; Guglielmi, 2019, 2020] and references therein). We will try to clarify to some extent this question, using results reported in recently published papers [Guglielmi, Klain, 2020; Kurazhkovskaya, 2020].

Kurazhkovskaya [2020] has used the number of magnetically quiet $\left(N_{\mathrm{q}}\right)$ and magnetically disturbed $\left(N_{\mathrm{d}}\right)$ days to characterize extreme conditions of the global magnetospheric disturbance. The selected series of $N_{\mathrm{q}}$ and $N_{\mathrm{d}}$ days characterizing geomagnetic conditions will be called Q- and D-periods respectively (quiet $(\mathrm{Q})$ and disturbed (D) periods). Kurazhkovskaya [2020] has found a number of interesting features in the dynamics of near-Earth space environment in a solar activity cycle. We believe that the proposed method for identifying the Q- and D-periods can also be used to study subtle effects of the interaction of plasma sheaths of the planet (ionosphere and magnetosphere) with the atmosphere, lithosphere, and technosphere.

In this paper, we focus on seismic activity of the lithosphere. To quantitatively describe seismic activity, we adopt the global daily magnitude (GDM) of earthquakes $M_{\mathrm{g}}$ introduced in [Guglielmi, Klain, 2020]:

$$
M_{\mathrm{g}}=\frac{1}{\beta} \ln \left[\frac{\sum_{j} H_{j} \exp \left(\beta M_{j}\right)}{\sum_{j} H_{j}}\right] .
$$

Here, $\beta=(3 / 2) \ln 10 ; j=1,2,3, \ldots$ numbers earthquakes recorded in the catalog during a calendar day; $M_{j}$ is the catalog earthquake magnitude with number $j$. The Heaviside symbol $H_{j}$ is 0 if $M_{j}<M_{0}$, and it is 1 if $M_{j} \geq M_{0}$, where $M_{0}$ is the lower boundary of the representative part of the earthquake catalog.

In this paper, we try to answer the question of whether there is a statistically significant difference in the global seismicity between extremely quiet and disturbed geomagnetic conditions. The results will be reviewed in the light of other studies on the subject.

\section{DATA AND ANALYSIS RESULTS}

To study experimentally the relationships between earthquakes and geomagnetic activity, we have used the databases created in [Guglielmi, Klain, 2019; Guglielmi, Klain, 2020; Kurazhkovskaya, 2020]. Information about earthquakes is presented as a series of 7300 GDM values calculated from Formula (1) for the 20-year period from 
1980 to 1999 , according to the Global Earthquake Cata$\log$ of The National Earthquake Information Center (NEIC) of the US Geological Survey [https://earthquake.usgs.gov/earthquakes]. We have found that the representative part of the $M_{\mathrm{g}}$ distribution of events satisfies the Gutenberg-Richter law [Kasahara, 1985] as follows [Guglielmi, Klain, 2020]:

$$
\log v=a-b M_{\mathrm{g}} \text {. }
$$

Here, $a=8.9, b=1.1, v$ is the frequency of events (by an event is meant a calendar day with a given GDM value).

The Q- and D-periods were identified using the method proposed in [Kurazhkovskaya, 2020]. The source material in the form of sums $\Sigma K_{\mathrm{p}}$ of the daily $K_{\mathrm{p}}$ index is taken from the website [http://wdc.kugi.kyotou.ac.jp/index.html] of the World Data Center for Geomagnetism, Kyoto. The Q-period is represented by an ordered series of days with $\Sigma K_{\mathrm{p}}<5$; and the D-period, by an ordered series of days with $\Sigma K_{\mathrm{p}}>25$. Over the period from 1980 to 1999,263 Q-days and 1918 D-days were amassed. To each day corresponds a certain value of the global daily magnitude $M_{\mathrm{g}}$.

In the course of this study, the database was supplemented: $M_{\mathrm{g}}$ series for Q- and D-days were continued to 2019. Nonetheless, here we confine our analysis to the period 1980-1999 since the data array selected for the statistical study should not only be as large as possible but also be sufficiently homogeneous. We have noticed that during the 40-year period the second condition is violated, namely after 2000 long-term trends in seismic and geomagnetic activity begin to emerge. The general tendency, which seems to be related to nonuniformity of the 11-year solar cyclicity, is that a slight decrease in geomagnetic activity is accompanied by a marked increase in earthquake activity.

We need to answer two questions: whether the $M_{\mathrm{g}}$ distribution of events during the Q-period differs from the distribution during the D-period, and, if there is a difference, how it manifests itself. By an event is meant a calendar day with a given $M_{\mathrm{g}}$ value.

Thus, we have to find out the relationship between two different objects, one of which is shown quantitatively $\left(M_{\mathrm{g}}\right)$; and the other, only qualitatively $(\mathrm{Q}, \mathrm{D})$. The probability theory and the mathematical statistics pro-

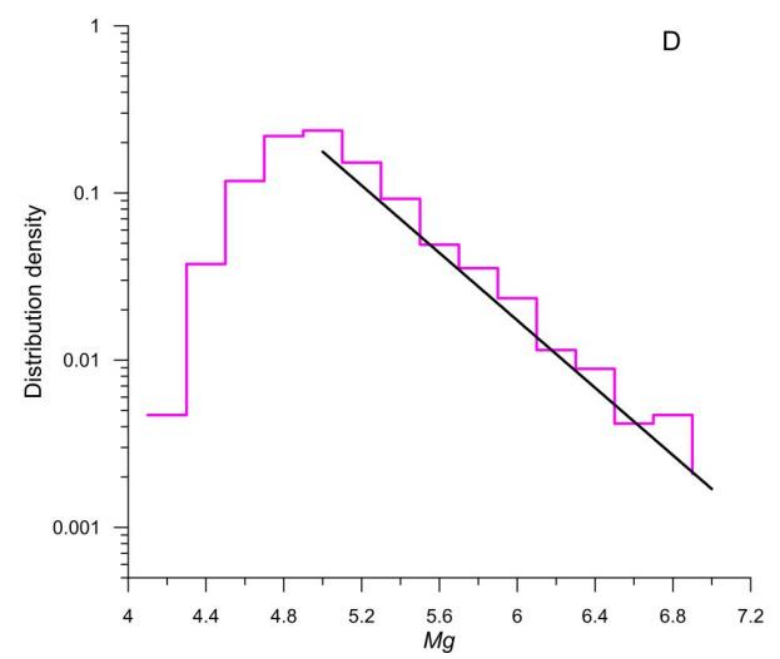

vide a broad set of tools to quantify the relationship between objects of this kind. At first, we assessed the empirical correlation ratio [Van der Waerden, 1960]. This ratio does not exceed 0.2 , which does not allow us to draw a conclusion about the existence of the desired relationship at a statistically significant level. Then, we adopted the Kolmogorov-Smirnov test [Chetyrkin, Kalikhman, 1982]. This is a non-parametric test, so it can be applied to the abnormal distributions we have found. It turned out that the hypothesis that our two sample distributions belong to the same general population should be rejected with an error probability of at most 0.05 .

So, the difference is likely to exist, but it is unclear in what exactly it manifests itself. Look at Figure 1. It shows densities of $M_{\mathrm{g}}$ distributions of events for the Dperiod (left panel) and for the Q-period (right panel). Straight lines fit representative parts of the distributions by Formula (2): for the D-period $a=4.28, b=1.0$; for the Q-period $a=3.17, b=0.8$.

Of particular interest to us are the slopes $b$ of the straight lines. The standard error in the estimated slope of the straight lines $\sigma= \pm 0.04$. The difference between the slopes is $\Delta b=0.2$, which is much greater than $3 \sigma$. The well-known three sigma rule is satisfied, we can therefore quite confidently assert that the planetary earthquake activity, characterized by $M_{\mathrm{g}}$, under extremely quiet geomagnetic conditions is significantly higher than under disturbed conditions. Note that a significant decrease in $b$ with time is sometimes considered as one of the predictors of a strong earthquake [Mogi, 1985; Sobolev, 1993].

The tendency for higher seismic activity under extremely quiet geomagnetic conditions we found is indirectly confirmed by the analysis of 35 earthquakes with $M=8$ and higher, which occurred in 1980-2019. The empirical probability of earthquakes with $M \geq 8$ on a Qday appeared to be $\sim 2$ times higher than on any other day. The respective values are $(4 \pm 0.6) \cdot 10^{-3}$ and $(2 \pm 0.2) \cdot 10^{-3}$. The difference between mean values exceeds $2 \sigma$. The difference can be considered significant with a probability of $95 \%$.

Figure 1. Density of event distribution by $M_{\mathrm{g}}$ under disturbed (left panel) and quiet (right panel) geomagnetic conditions 


\section{DISCUSSION}

In seismoelectrodynamics, two lines of research have formed, which can be called theoretical and empirical. The theoretical line involves studying the conversion of the mechanical energy of rocks into the energy of the electromagnetic field through various physical mechanisms such as piezomagnetic [Kalashnikov, Kapitsa, 1952; Nagata, 1970], inductive [Eleman, 1966], and inertial [Guglielmi, 1992a]. The theory predicts the excitement of rather weak seismomagnetic signals, which are quite difficult to detect against instrumental, cosmic, and man-made interference. Methods of interference suppression are discussed in detail in [Guglielmi, 2007].

The empirical approach we use involves searching experimentally for dynamic effects of electromagnetic fields on rocks in situ. Generally speaking, strong physical and mathematical bases for this research are not yet available, but there is a wealth of experience of observation of correlations between earthquakes and accompanying geomagnetic and solar phenomena (see recent research into correlations of this kind [Atmospheric and ionospheric electromagnetic phenomena ..., 1999;. Sobolev et al., 2001; Hattori, 2004; Sobisevich et al., 2010; Tarasov, 2010; Strakhov, Savin, 2013; Guglielmi, Klain, 2020; Sobolev et al., 2020]).

Two approaches to searching for mechanisms of impact of the electromagnetic field on the dynamics of rocks were previously known. One of them is based on the concept of force effect [Guglielmi, 1992b]; the other, on the concept of thermal effect [Fainberg et al., 2004] of the alternating electromagnetic field. The calculation results give no reason to believe that the force and thermal effects of the electromagnetic field plays a role in the dynamics of the lithosphere. Recently, it has been hypothesized that the alternating magnetic field alters the ductility of rocks, and this leads to a noticeable change in seismic activity [Buchachenko, 2019]. The theory [Buchachenko, 2019] also predicts activation of strong earthquakes at low geomagnetic activity. Our results qualitatively confirm this prediction.

In concluding this section, we present Figure 2. Panels depict the long-term evolution of the following parameters (top to bottom): the annual number of extremely quiet days $N_{\mathrm{Q}}$ [Kurazhkovskaya, 2020], the annual number $N_{\text {eq }}$ of earthquakes with $M \geq 5$, the annual value of $\operatorname{GDM}\left(M_{\mathrm{g}}\right)$, and the annual entropy $S$ :

$$
S=\ln Z+\eta<M>,
$$

where $Z=\sum_{j} H_{j} \exp \left(-\eta M_{j}\right)$ is the statistical sum in the earthquake ensemble $\langle M>=-\partial \ln Z / \partial \eta$ [Guglielmi, Klain, 2020].

Evolution of these parameters is quite interesting. The significant increase in $N_{\mathrm{Q}}$ in the second half of the 40 -year period is unequivocally related to the nonuniformity of Schwabe-Wolf solar cycles, as we have mentioned in the previous section of this paper.

Particularly noteworthy is the variation in $N_{\text {eq }}$ : the significant increase in the number of extremely quiet

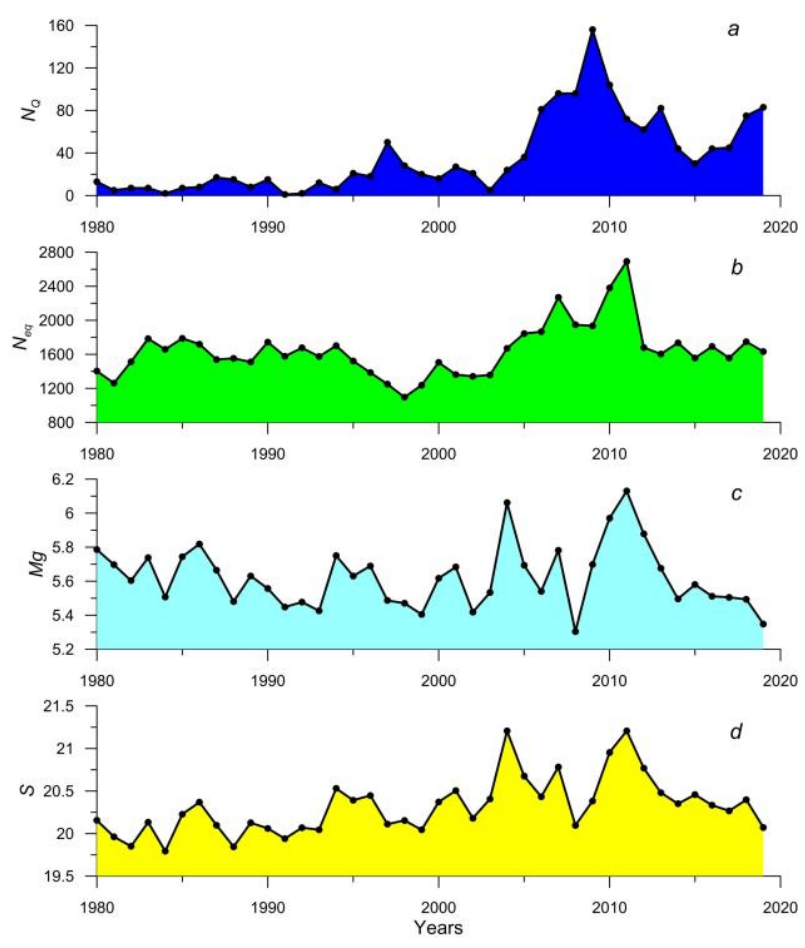

Figure 2. Long-term variation in geophysical parameters characterizing geomagnetic and seismic activity: $N_{\mathrm{Q}}$ is the annual number of extremely quiet days [Kurazhkovskaya, 2020] (a); $N_{\mathrm{eq}}$ is the annual number of earthquakes with $M \geq 5(b)$; $M_{\mathrm{g}}$ is the annual value of $\operatorname{GDM}(c) ; S$ is the annual entropy $(d)$

days since 2004 is seen to occur with a marked increase in seismic activity. This is consistent both with the prediction made in [Buchachenko, 2019] and with the analysis result reported in the previous section of this paper. Comparing variations of these parameters calls for additional analysis. Sometimes, in such cases, pair correlation coefficients $R$ are shown. The crosscorrelation analysis has revealed that, for example, for the pair $\left(N_{\mathrm{Q}}, N_{\mathrm{eq}}\right) R=0.75$; for the pairs of parameters $\left(N_{\mathrm{Q}}, M_{\mathrm{g}}\right)$ and $\left(N_{\mathrm{Q}}, S\right) R=0.70$. The value $R$ seems to quantitatively confirm the visual impression about the relationship between these parameter pairs, but the correlation coefficient itself does not matter much. We do not think that $R$ sufficiently accurately reflects the relationship between the parameters. In fact, the GDM variation is caused not only by exogenous triggers, but also by powerful endogenous processes leading to earthquakes.

\section{CONCLUSION}

We have adopted the method of identifying extremely quiet and disturbed periods in magnetospheric conditions, which has been put forward in [Kurazhkovskaya, 2020], to comparative analysis of earthquake distribution by the global daily magnitude in the periods under study. We have found that under extremely quiet geomagnetic conditions the probability of occurrence of strong earthquakes is noticeably higher. The result qualitatively confirms the prediction made in [Buchachenko, 2019] on the basis of physico-chemical interpretations of change in ductility of solids under the action of alternating magnetic fields. 
We are grateful to A.L. Buchachenko for fruitful discussion of problems of magnetoplasticity, which largely contributed to presentation of this work. We sincerely thank A.D. Zavyalov, O.D. Zotov, and A.S. Potapov for their interest in the work and valuable comments. The work was supported by project of the Ministry of Education and Science of the Russian Federation KP19-270 "Questions about origin and evolution of the Universe: using methods of ground-based observations and space research" (project $28 \mathrm{P}$ ) under the state tasks of the Schmidt Institute of Physics of the Earth RAS, RFBR project 18-05-00096, and State task No. 0144-2014-00116 of the IPE RAS Geophysical Observatory Borok.

\section{REFERENCES}

Atmospheric and Ionospheric Electromagnetic Phenomena Associated with Earthquakes. Tokyo, Terra Scientific Publishing Company, 1999, 996 p.

Bauer L.A. Magnetograph records of earthquakes with special reference to the San Francisco earthquake of April 18, 1906. Terrestrial Magnetism and Atmospheric Electricity. 1906, vol. XI, pp. 135-144. DOI: 10.1029/TE011i003p00135.

Buchachenko A.L. Microwave stimulation of dislocations and the magnetic control of the earthquake core. PhysicsUspekhi. 2019, vol. 62, no. 1, pp. 46-53. DOI: 10.3367/UFNe. 2018.03.038301.

Chetyrkin E.M., Kalikhman I.L. Veroyatnost' $i$ statistika [Probability and Statistics]. Moscow, Financy i statistika Publ., 1982, 319 p. (In Russian).

Davison Ch. The Founders of Seismology. Cambridge, University Press, 1927, pp. 203-223.

Eleman F. The response of magnetic instruments to earthquake waves. J. Geomag. Geoelectr. 1966, vol. 18, no. 1, pp. 43-72. DOI: 10.5636/jgg.18.43.

Fainberg E.B., Avagimov A.A., Zeigarnik V.A., Vasil'eva T.A. Generation of heat flows in the Earth's interior by global geomagnetic storms. Izvestiya, Physics of the Solid Earth. 2004, vol. 40, no. 4, pp. 315-322.

Guglielmi A.V. Elastomagnetic waves in a porous medium. Physica Scripta. 1992a, vol. 46, pp. 433-434.

Guglielmi A.V. Ponderomotive forces in the crust and magnetosphere of the Earth. Fizika Zemli [Izvestiya, Physics of the Solid Earth]. 1992b, no. 7, pp. 35-39. (In Russian).

Guglielmi A.V. Ultra-low-frequency electromagnetic waves in the Earth's crust and magnetosphere. PhysicsUspekhi. 2007, vol. 50, no. 12, pp. 1197-1216. DOI: 10.1070/ PU2007v050n12ABEH006413.

Guglielmi A.V. Omori's law: a note on the history of geophysics. Physics-Uspekhi. 2017, vol. 60, no. 3, pp. 319-324. DOI: 10.3367/UFNe.2017.01.038039.

Guglielmi A.V. History of formation of the seismoelectrodynamics. Nauka i tekhnologicheskie razrabotki [Science and Technological Developments]. 2019, vol. 98, no. 1, pp. 5-20. [Special issue "Methodological Aspects of the Application of Electromagnetic Methods in Geophysical Research"]. DOI: 10.21455/std2019.1-1. (In Russian).

Guglielmi A.V. On the relationship between earthquakes and geomagnetic disturbances. Geofizicheskie issledovaniya [Geophys. Res.]. 2020, vol. 21, no. 2, pp. 7984. DOI: 10.21455/gr2020.2-6. (In Russian).

Guglielmi A.V., Klain B.I. Global magnitude of the earthquakes. Arxiv. 2019. arXiv:1909.00879v1. https://arxiv.org/ abs/1909.00879v1. (accessed June 6, 2020).
Guglielmi A.V., Klain B.I. Effect of the Sun on Earth's seismicity. Solar-Terr. Phys. 2020, vol. 6, no. 1, pp. 89-92. DOI: $10.12737 /$ stp-61202010.

Guglielmi A.V., Zavyalov A.D. The Omori law: The 150year birthday jubilee of Fusakichi Omori. J. Volcanolog. Seismol. 2018, vol. 12, no. 5 pp. 353-358. DOI: 10.1134/ S0742046318050044.

Hattori K. ULF Geomagnetic changes associated with large earthquakes. TAO. 2004, vol. 15, no. 3, pp. 329-360.

Kalashnikov A.G., Kapitsa S.P. Magnetic susceptibility of rocks at elastic stresses. Doklady Akademii nauk SSSR [Doklady of the Academy of Sciences of the USSR]. 1952, vol. 86, no. 3, pp. 521-523. (In Russian).

Kasahara K. Mekhanika zemletryasenii [Earthquake Mechanics]. Moscow, Mir Publ., 1985, 264 p. (In Russian). (English edition: Kasahara K. Earthquake Mechanics. Cambridge University Press, 1981. 284 p.)

Kurazhkovskaya N.A. Global disturbance of Earth's magnetosphere and its connection with space weather. Solar-Terr. Phys. 2020, vol. 1, no. 1, pp. 41-49. DOI: 10.12737/stp61202005 .

Mascart M. On magnetic effects of earthquakes. C.R. Acad. Sci. Paris, 1887, vol. CLV, pp. 607-608. (In French).

Mogi K. Earthquake Prediction. Tokio, Academic Press, 1985, $355 \mathrm{p}$.

Nagata T. Basic magnetic properties of rocks under the effect of mechanical stresses. Tectonophysics. 1970, vol. 9, no. 23, pp. 167-195.

Orlov A.P. Zemletryaseniya i ikh sootnosheniya s drugimi yavleniyami prirody [Earthquakes and Their Relationships with Other Natural Phenomena]. Kazan, 1887, 170 p. (In Russian).

Sobisevich L.E., Kanonidi K.K., Sobisevich A.L. Observations of ultra-low-frequency geomagnetic disturbances reflecting the processes of the preparation and development of tsunamigenic earthquakes. Doklady. Earth Sciences. 2010, vol. 435, pp. 627-632. DOI: 10.1134/S1028334X10120160.

Sobolev G.A. Osnovy prognoza zemletryasenii [Fundamentals of Earthquake Prediction]. Moscow, Nauka Publ., 1993, 312 p. (In Russian).

Sobolev G.A., Zakrzhevskaya N.A., Kharin E.P. On the relation between seismicity and magnetic storms. Izvestiya, Physics of the Solid Earth. 2001, vol. 37, no. 11, pp. 917-927.

Sobolev G.A., Zakrzhevskaya N.A., Migunov I.N., Sobolev D.G., Boiko A.N. Effect of magnetic storms on lowfrequency seismic noise. Izvestiya, Physics of the Solid Earth. 2020, vol. 56, no. 3, pp. 291-315.

Strakhov V.N., Savin M.G. On the management of seismic activity. Geofizicheskii Zhurnal [Geophysical Journal]. 2013, vol. 35, no. 6, pp. 3-9. (In Russian).

Tarasov N.T. Influence of strong electromagnetic fields on the seismotectonic strain rate. Doklady Earth Sciences. 2010, vol. 433, Part 2, pp. 1088-1091. DOI: 10.1134/S1028334X 10080210.

Van der Varden B.L. Matematicheskaya statistika [Mathematical Statistics]. Moscow, Izdatel'stvo inostrannoi literatury, 1960, 434 p. (In Russian). (English edition: Van der Waerden B.L. Mathematical Statistics. Springer-Verlag Berlin Heidelberg, 1969, 371 p.)

URL: http://swdcwww.kugi.kyoto-u.ac.jp/index.html (accessed January 30, 2020)

URL: https://earthquake.usgs.gov/earthquakes (accessed March 12, 2020).

How to cite this article

Guglielmi A.V., Klain B.I., Kurazhkovskaya N.A. Earthquakes and geomagnetic disturbances. Solar-Terrestrial Physics. 2020. Vol. 6. Iss. 4. P. 80-83. DOI: 10.12737/stp-64202012. 